\title{
Formation of Supersaturated Solid Solutions Bi-Ag and Bi-Zn by Rapid Solidification Using Melt Spinning Technique
}

\author{
Tarek El-Ashram ${ }^{1,2}$ \\ ${ }^{1}$ Physics Department, Faculty of Science, Port Said University, Port Said, Egypt \\ ${ }^{2}$ Physics Department, Preparatory Year Deanship, Jazan University, Jazan, KSA \\ Email: tnelashram@gmail.com
}

Received 18 January 2015; accepted 9 February 2015; published 12 February 2015

Copyright (c) 2015 by author and Scientific Research Publishing Inc.

This work is licensed under the Creative Commons Attribution International License (CC BY). http://creativecommons.org/licenses/by/4.0/

(c) (i) 0pen Access

\begin{abstract}
Two eutectic alloys Bi-Ag and Bi-Zn were rapidly solidified using melt-spinning technique. X-ray diffraction analysis (XRD), differential scanning calorimetry (DSC), and temperature dependence of resistivity (TDR) were performed. The solid solubility of both $\mathrm{Ag}$ and $\mathrm{Zn}$ was extended to the eutectic concentration due to rapid solidification by melt spinning technique and both alloys are single-phase solid solutions. The addition of Ag extended the unit cell in both a and c directions keeping the axial ratio $\mathrm{c} / \mathrm{a}$ without change, and in case of $\mathrm{Zn}$ addition, the unit cell was increased in a direction and decreased in c direction leading to the decrease in the axial ratio c/a. The Bi-Ag eutectic alloy exhibited a semiconducting behavior with energy gap of $280 \mathrm{meV}$, while Bi-Zn eutectic alloy exhibited metallic behavior.
\end{abstract}

\section{Keywords}

Rapid Solidification (RS), Crystal Structure, X-Ray Diffraction Analysis (XRD), Solid Solubility, Semiconducting Behavior, Bi-Ag, Bi-Zn

\section{Introduction}

Nowadays rapid solidification technology is used in manufacturing semiconductors. Rapid solidification can produce semiconductor alloys not normally obtained by conventional methods. The semiconductors prepared by rapid solidification exhibit considerable improvements over alloys made from conventional materials. The thermoelectric materials fabricated by rapid solidification displayed a high figure of merit [1]. Formation of dendritic structure in thermoelectric alloys impairs its thermoelectric parameters [2]-[6]. Several authors studied the ef- 
fect of alloying on the electronic and the electrical properties of Bi; they found that the addition of antimony changes the electrical behavior from semimetal to semiconductor at a certain range of concentration of Sb [7]-[9]. A series of rapidly solidified Bi-based semiconductor alloys are produced using melt spinning technique [10] [11]. They found that the semiconducting behavior depends on the type of the solute atoms added to Bi. The alloys contain solute atoms with odd valencies: for instance, $\mathrm{Ag}(+1)$, $\mathrm{Al}(+3)$ and $\mathrm{Sb}(+5)$ have semiconducting behavior by contrast; all alloys contain solute atoms with even valencies: for instance Zn (+2) and Sn (+4) have metallic behavior. According to the equilibrium Bi-Ag phase diagram, there is no solubility of Ag in $\mathrm{Bi}$ [12]. By rapid solidification using melt spinning technique, the solubility of $\mathrm{Ag}$ in $\mathrm{Bi}$ is extended to $2 \mathrm{at} \%$ [10]. There are significant discrepancies concerning the solubility limit of $\mathrm{Zn}$ in Bi prepared by conventional casting. Recent investigations indicate that the solubility of $\mathrm{Zn}$ in $\mathrm{Bi}$ is $0.3 \mathrm{wt} \%$ at $200^{\circ} \mathrm{C}$ [13] [14]. In contrast some authors found that the solubility of $\mathrm{Zn}$ in $\mathrm{Bi}$ is $2 \mathrm{wt} \%$ [15]. Therefore, the aim of the present work is to study the effect of increasing Ag and $\mathrm{Zn}$ concentrations on the structure and electrical properties of Bi. Rapid solidification has been used in the present work to prevent rejection of extra solute atoms and thus prevent precipitation, from a solid solution.

\section{Experimental Procedures}

The materials used in the present work are $\mathrm{Bi}, \mathrm{Ag}$ and $\mathrm{Zn}$ fragments the starting purity was better than 99.99\%. Two alloys Bi- 4.3 at\% Ag (eutectic) and Bi-8.1 at\% Zn (eutectic) were produced by a single copper roller (200 $\mathrm{mm}$ in diameter) melt-spinning technique. The process parameters such as the ejection temperature, and the linear speed of the wheel were fixed at $873 \mathrm{~K}$ and $30.4 \mathrm{~ms}^{-1}$ respectively. X-ray diffraction analysis (XRD) was carried out with a XPERT-PRO X-ray diffractometer, using $\mathrm{Cu}-\mathrm{K}_{\alpha}$ radiation $(\lambda=1.5406 \AA)$. Differential Scanning Calorimetry (DSC) was carried out in a Shimadzu (DSC-50) with heating rate $10 \mathrm{~K} \cdot \mathrm{min}^{-1}$. The temperature dependence of resistivity (TDR) was measured by four probe method using micro ohmmeter of type BS407. The BS407 uses a four terminal measurement system via high quality Kelvin Clip leads with sensitivity is $1 \mu \Omega$. The heating range starts from room temperature up to $530 \mathrm{~K}$ with heating rate about $5 \mathrm{~K} \cdot \mathrm{min}^{-1}$.

\section{Results and Discussion}

\subsection{Structure}

Figure 1(a) shows the X-ray diffraction pattern for as-quenched melt-spun Bi-4.7 at\% Ag eutectic alloy. All the

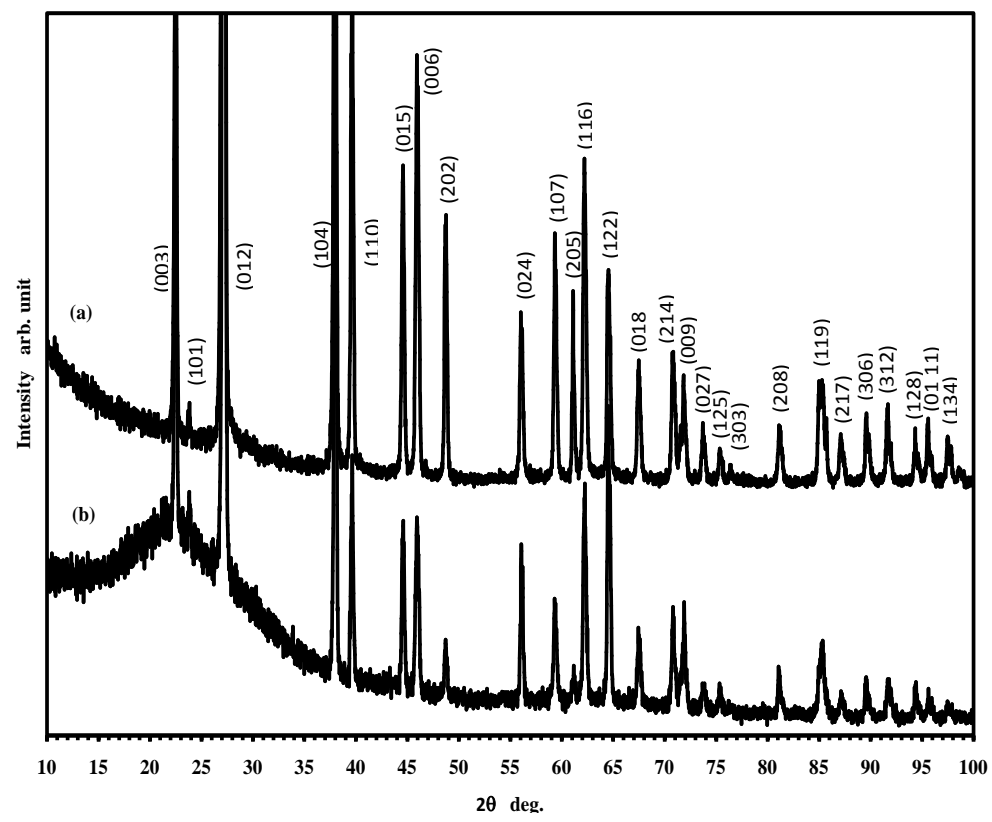

Figure 1. X-ray diffraction pattern for as-quenched melt-spun: (a) Bi-4.7 at\% Ag eutectic alloy; (b) Bi-8.1 at\% Zn eutectic alloy. 
peaks were identified for Bi rhombohedral structure. No precipitation of Ag was observed and the structure is a single phase Bi rich solid solution of $\mathrm{Ag}$ in $\mathrm{Bi}$. According to the equilibrium phase diagram there no solubility of $\mathrm{Ag}$ in $\mathrm{Bi}$. Therefore rapid solidification by melt spinning technique extended the solubility of $\mathrm{Ag}$ in $\mathrm{Bi}$ up to the eutectic composition. The structure of $\mathrm{Bi}$ is rhombohedral-hexagonal (S.G.: $R \overline{3} \mathrm{~m}$ ) with lattice parameters [16] $a=4.745 \AA, \alpha=57.23^{\circ}$. Alternatively, the lattice parameters can be specified as the corresponding hexagonal vectors, with lengths $a=4.546 \AA$ and $c=11.862 \AA$.

By addition of $\mathrm{Ag}$ to $\mathrm{Bi}$, the lattice parameters of $\mathrm{Bi}$ were increased (see Table 1). However the axial ratio c/a did not change. Also the volume of unit cell was increased. The intensity ratio from (110) to (012) planes was decreased from $29 \%$ to $14.64 \%$. The particle size of $\mathrm{Bi}$ was calculated using Debye-Scherrer formula [17] to be $343.4 \AA$.

Figure 1(b) shows the X-ray diffraction pattern for as-quenched melt-spun Bi-8.1 at\% Zn eutectic alloy. All the peaks were identified for $\mathrm{Bi}$ rhombohedral structure. No precipitation of $\mathrm{Zn}$ was observed and the structure is a single phase $\mathrm{Bi}$ rich solid solution of $\mathrm{Zn}$ in $\mathrm{Bi}$. Therefore rapid solidification by melt spinning technique extended the solubility of $\mathrm{Zn}$ in $\mathrm{Bi}$ up to the eutectic composition. The lattice parameter a is increased and c is decreased and this led to the decrease in the axial ratio c/a (see Table 1). The volume of the unit cell $v$ is increased from 212.298 to $212.608 \AA^{3}$. The intensity ratio from (110) plane to (012) plane was decreased from $29 \%$ to $6.74 \%$. The particle size was calculated to be $330.7 \AA$. The detail of XRD is shown in Table 1.

\subsection{Thermal Analysis}

Figure 2 shows the DSC curves for as-quenched melt-spun Bi-4.7 at\% $\mathrm{Ag}$ and Bi-8.1 at\% $\mathrm{Zn}$ alloys.

For Bi-4.7 at\% Ag (Figure 2(a)) no phase transformation was observed before melting. The melting endotherm is a single sharp peak which characterizes the eutectic reaction. The melting temperature $\mathbf{T}_{\mathbf{m}}$ was found to be $534.37 \mathrm{~K}$. The enthalpy of fusion $\Delta \mathbf{H}_{\mathbf{m}}$ was calculated to be $57.67 \mathrm{~kJ} \cdot \mathrm{kg}^{-1}$. The same behavior was observed for Bi-8.1 at\% Zn (Figure 2(b)).

Table 1. The detail of XRD results of rapidly solidified Bi- based alloys.

\begin{tabular}{|c|c|c|c|c|c|c|c|c|}
\hline \multirow{2}{*}{ Alloy } & \multirow{2}{*}{$\begin{array}{l}\text { Phases } \\
\text { present }\end{array}$} & \multirow{2}{*}{ Crystal structure } & \multicolumn{4}{|c|}{ The lattice parameters of $\mathrm{Bi}$ crystal } & \multirow{2}{*}{$\mathbf{I}_{(\mathbf{1 1 0})} / \mathbf{I}_{(\mathbf{0 1 2})}$} & \multirow{2}{*}{$\begin{array}{c}\text { Particle } \\
\text { size } \AA\end{array}$} \\
\hline & & & a $\AA$ & c Å & $\mathbf{c} / \mathbf{a}$ & $v \AA^{3}$ & & \\
\hline Pure Bi & $\mathrm{Bi}$ & $\begin{array}{c}\text { Rhombohedral-hexagonal } \\
\text { (S.G.: } \quad R \overline{3} m \text { ) }\end{array}$ & 4.546 & 11.862 & 2.6093 & 212.298 & 29.0 & - \\
\hline $\mathrm{Bi}-4.7 \mathrm{Ag}$ & $\mathrm{Bi}^{*}$ & $\begin{array}{l}\text { Rhombohedral-hexagonal } \\
\text { (S.G.: } R \overline{3} m \text { ) }\end{array}$ & 4.5482 & 11.8679 & 2.6093 & 212.609 & 14.64 & 343.4 \\
\hline $\mathrm{Bi}-8.1 \mathrm{Zn}$ & $\mathrm{Bi}^{\#}$ & $\begin{array}{l}\text { Rhombohedral-hexagonal } \\
\text { (S.G.: } R \overline{3} m \text { ) }\end{array}$ & 4.5531 & 11.8423 & 2.6009 & 212.608 & 6.74 & 330.7 \\
\hline
\end{tabular}

$\mathrm{Bi}^{*}$ : Solid solution of $\mathrm{Ag}$ in $\mathrm{Bi}$; $\mathrm{Bi}^{*}$ : Solid solution of $\mathrm{Zn}$ in $\mathrm{Bi}$.

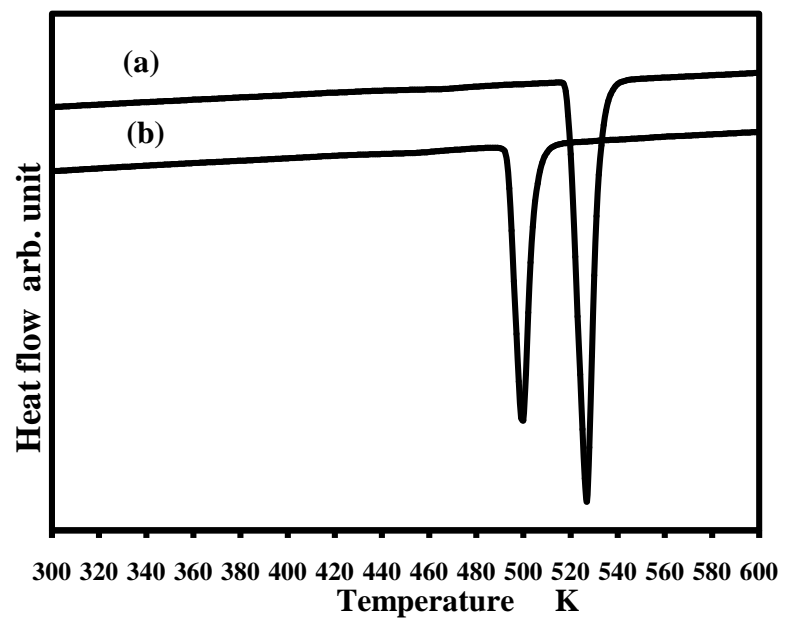

Figure 2. DSC curves for as-quenched melt-spun: (a) Bi-4.7 at\% Ag eutectic alloy; (b) Bi-8.1 at\% Zn eutectic alloy. 
No phase transformation was observed before melting and the melting endotherm is a single sharp peak which characterizes the eutectic reaction. The melting temperature $\mathbf{T}_{\mathbf{m}}$ was found to be $527.45 \mathrm{~K}$ and the enthalpy of fusion $\Delta \mathbf{H}_{\mathbf{m}}$ was found to be $61.26 \mathrm{~kJ} \cdot \mathrm{kg}^{-1}$. The detail of DSC is shown in Table 2.

\subsection{Electrical Properties}

Figure 3(a) shows the TDR curves obtained for as-quenched melt-spun Bi-4.7 at\% Ag alloy. The resistivity decreases by increasing temperature i.e. it has a semiconducting behavior.

The resistivity at room temperature of pure $\mathrm{Bi}$ is $1.17 \mu \Omega \mathrm{m}$ and TCR is $4.6 \times 10^{-3} \mathrm{~K}^{-1}$ [18]. Pure Bi was rapidly solidified by melt spinning technique and its resistivity was measured to be $2.09 \mu \Omega \mathrm{m}$ and TCR was found to be $3.05 \times 10^{-3} \mathrm{~K}^{-1}$ [19]. Therefore rapid solidification increases the resistivity of Bi and decreases the TCR. The energy gap was calculated and was found to be $280 \mathrm{meV}$. The increase in $\mathrm{Ag}$ concentration increases the energy gap of as quenched melt spun semiconducting Bi-Ag alloy from $225 \mathrm{meV}$ for $\mathrm{Bi}-1$ at\% $\mathrm{Ag}$ [10] to 280 $\mathrm{meV}$ for Bi-Ag eutectic alloy. The explanation of the semiconducting behavior of $\mathrm{Bi}$ alloys is given elsewhere [20].

Figure 3(b) shows the TDR curves obtained for as-quenched melt-spun Bi-8.1 at\% $\mathrm{Zn}$ alloy. The resistivity increases by increasing temperature i.e. it has a metallic behavior. The resistivity at room temperature was found to be $14.25 \mu \Omega \mathrm{m}$ and TCR was found to be $3.38 \times 10^{-3} \mathrm{~K}^{-1}$. Both $\rho$ and TCR were increased due to the addition of Zn (see Table 3).

Table 2. The detail of DSC results of rapidly solidified Bi-based alloys.

\begin{tabular}{ccc}
\hline Alloy & $\mathbf{T}_{\mathbf{m}} \mathbf{K}$ & $\mathbf{\Delta H}_{\mathbf{m}} \mathbf{k J} \cdot \mathbf{k g}^{-\mathbf{1}}$ \\
\hline Pure Bi & 544.5 & 54.07 \\
Bi-4.7 Ag & 534.37 & 57.67 \\
Bi-8.1 Zn & 527.45 & 61.26 \\
\hline
\end{tabular}

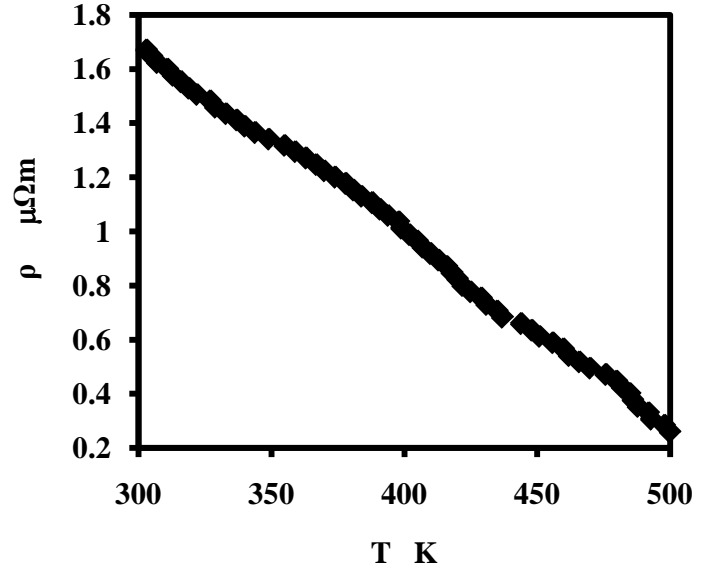

(a)

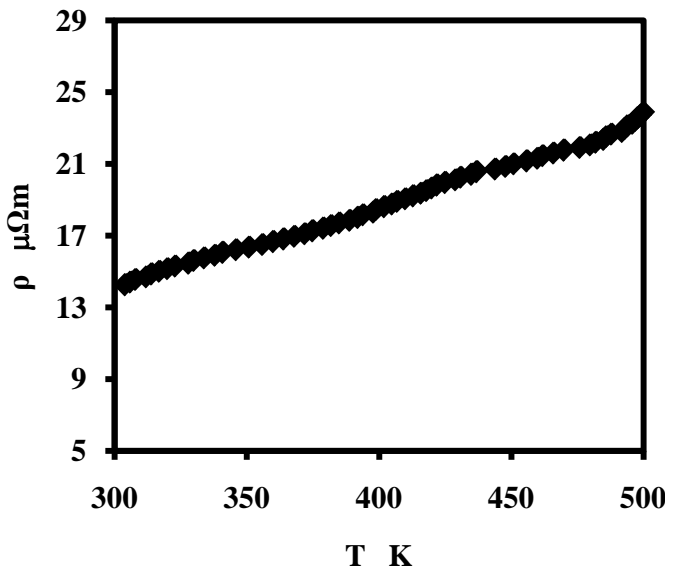

(b)

Figure 3. TDR curves obtained for as-quenched melt-spun: (a) Bi-4.7 at\% Ag eutectic alloy; (b) Bi-8.1 at\% Zn eutectic alloy.

Table 3. The detail of TDR results of rapidly solidified Bi-based alloys.

\begin{tabular}{|c|c|c|c|c|}
\hline Alloy & $\rho \mu \Omega \mathrm{m}$ at room temp. & Behavior & $\operatorname{TCR} 10^{-3} \mathrm{~K}^{-1}$ & $E_{g}(m e V)$ \\
\hline Pure Bi (CC) & 1.17 & Metallic & 4.60 & - \\
\hline Pure Bi (RS) & 2.09 & Metallic & 3.05 & - \\
\hline Bi-4.7 Ag (RS) & 1.67 & Semiconducting & - & 280 \\
\hline Bi-8.1 Zn (RS) & 14.25 & Metallic & 3.38 & - \\
\hline
\end{tabular}

CC: conventional casting; RS: rapid solidification. 


\section{Conclusions}

From this work, the following conclusions may be obtained:

1) Rapid solidification using melt-spinning technique can produce semiconductor alloys, which cannot be normally obtained by conventional casting. The rapidly solidified Bi-Ag eutectic alloy was found to be a narrow gap semiconductor. Also by increasing Ag concentration, the energy gap increased from $225 \mathrm{meV}$ for $\mathrm{Bi}-1$ at\% $\mathrm{Ag}$ [10] to $280 \mathrm{meV}$ for Bi-Ag eutectic alloy.

2) From the XRD it is evident that the solid solubility of both Ag and Zn was extended to the eutectic concentration due to rapid solidification by melt spinning technique. Also the addition of both Ag and $\mathrm{Zn}$ to Bi increases the volume of the unit cell. However Ag extends the unit cell in both a and c directions keeping the axial ratio c/a without change, and in case of $\mathrm{Zn}$ the unit cell is increased in a direction and decreased in c direction leading to the decrease in the axial ratio c/a.

3) The increase in the Zn concentration in Bi did not lead to any semiconducting behavior. This indicates that the odd valency dopants are responsible on converting Bi into semiconductor as suggested by [11].

4) The melting endotherm of the supersaturated solid solutions was a single sharp peak, i.e. the same as the eutectic melting.

\section{References}

[1] Horio, Y., Yamashita, H. and Hayashi, T. (2004) Microstructure and Thermoelectric Properties of Hot-Pressed p-Type $\mathrm{Bi}_{0.5} \mathrm{Sb}_{1.5} \mathrm{Te}_{3}$ Alloys Prepared by Rapid Solidification Technique. Materials Transactions, 45, 3309-3313. http://dx.doi.org/10.2320/matertrans.45.3309

[2] Shepelevich, V.G. and Prokoshin, V.I. (2014) Electrical Properties of Rapidly Solidified of Heavily Doped Alloys $\left(\mathrm{Bi}_{91}-\mathrm{Sb}_{9}\right)_{100-\mathrm{x}} \mathrm{Sn}_{\mathrm{x}}$. 8th International Conference on Microelectronics and Computer Science, Chisinau, October 2014, 22-25.

[3] Shepelevich, V.G. (1986) Homogenizing Influence on the Kinetic Properties of Alloys of Bi-Sb. Inorganic Materials, 22, 378-380.

[4] Koukharenko, E., Frety, N., Shepelevich, V.G. and Tedenac, J.C. (2001) Microstructural Characterization of Ultrarapid Quenched Bismuth and Antimony Tellurides Alloys. Journal of Crystal Growth, 222, 773-778. http://dx.doi.org/10.1016/S0022-0248(00)00996-9

[5] Koukharenko, E., Frety, N., Shepelevich, V.G. and Tedenac, J.C. (2000) Thermoelectric Properties of $\mathrm{Bi}_{2} \mathrm{Te}_{3} \mathrm{Material}$ Obtained by the Ultarapid Quenching Process Route. Journal of Alloys and Compounds, 299, 254-257. http://dx.doi.org/10.1016/S0925-8388(99)00688-X

[6] Koukharenko, E., Frety, N., Shepelevich, V.G. and Tedenac, J.C. (2001) Electrical Properties $\mathrm{Bi}_{2-\mathrm{x}} \mathrm{Sb}_{\mathrm{x}} \mathrm{Te}_{3} \mathrm{Materials}$ Obtained by Ultrarapid Quenching. Journal of Alloys and Compounds, 327, 1-4. http://dx.doi.org/10.1016/S0925-8388(01)00945-8

[7] Dutta, S., Shubha, V., Ramesh, T.G. and D’Sa, F. (2009) Thermal and Electronic Properties of Bi ${ }_{1-\mathrm{x}} \mathrm{Sb}_{\mathrm{x}} \mathrm{Alloys}$ Journal of Alloys and Compounds, 467, 305. http://dx.doi.org/10.1016/j.jallcom.2007.11.146

[8] Lenoira, B., Dauscher, A., Cassartb, M., Ravichc, Y.I. and Scherrer, H. (1998) Effect of Antimony Content on the Thermoelectric Figure of Merit of $\mathrm{Bi}_{1-\mathrm{x}} \mathrm{Sb}_{\mathrm{x}}$ Alloys. Journal of Physics and Chemistry of Solids, 59, 129. http://dx.doi.org/10.1016/S0022-3697(97)00187-X

[9] Lenoira, B., Cassartb, M., Michenaud, J.P., Scherrer, H. and Scherrer, S. (1996) Transport Properties of Bi-RICH Bi-Sb Alloys. Journal of Physics and Chemistry of Solids, 57, 89-99. http://dx.doi.org/10.1016/0022-3697(95)00148-4

[10] Raouf, A., Kamal, M., El Ashram, T. and Mosaad, S. (2010) Rapidly Solidified Semiconducting Bi-Ag Alloys Produced Using Melt-Spinning Technique. Journal of Ovonic Research, 6, 297-302.

[11] El-Ashram, T., Kamal, M., Raouf, M.A. and Mosaad, S. (2012) Odd Valency Dopants Convert Bismuth into Semiconductor. Journal of Ovonic Research, 8, 97-104.

[12] Hansen, M. and Anderko, K. (1958) Constitution of Binary Alloys. 2nd Edition, McGraw-Hill, Inc., New York, 10-11.

[13] Malakhov, D.V. (2000) Thermodynamic Assessment of the Bi-Zn System. Calphad, 24, 1-14. http://dx.doi.org/10.1016/S0364-5916(00)00011-0

[14] Braga, M.H., Vizdal, J., Kroupa, A., Ferreira, J., Soares, D. and Malheiros, L.F. (2007) The Experimental Study of the Bi-Sn, Bi-Zn and Bi-Sn-Zn Systems. CALPHAD, 31, 468-478.

[15] Massalski, T.B. (1990) Binary Alloy Phase Diagrams. ASM International, Ohio.

[16] McClune, W.F., Ed. (1988) Selected Powder Diffraction Data for Education \& Training, Search Manual and Data 
Cards. JCPDS, International Center for Diffraction Data, Swarthmore.

[17] Cullity, B.D. (1959) Elements of X-Ray Diffraction. 2nd Edition, Addison-Wesley Publishing Company, Reading, 262, 317.

[18] Smithells, C.J. and Brandes, E.A. (1976) Metals Reference Book. 5th Edition, Butterworth and Co. Ltd., UK, 940.

[19] Kamal, M. and El-Ashram, T. (2008) Zero and Negative Temperature Coefficients of Resistivity of Rapidly Solidified Bi-Sn Alloys Using Melt-Spinning Technique. Journal of Materials Science: Materials in Electronics, 19, 91-96. http://dx.doi.org/10.1007/s10854-007-9315-4

[20] Dey, K.K., Banerjee, D. and Bhattacharya, R. (2002) Magnetic Properties of Single Crystal of Bismuth Doped with Gallium and Indium. Fizika A (Zagreb), 11, 153-162. 
Scientific Research Publishing (SCIRP) is one of the largest Open Access journal publishers. It is currently publishing more than 200 open access, online, peer-reviewed journals covering a wide range of academic disciplines. SCIRP serves the worldwide academic communities and contributes to the progress and application of science with its publication.

Other selected journals from SCIRP are listed as below. Submit your manuscript to us via either submit@scirp.org or Online Submission Portal.
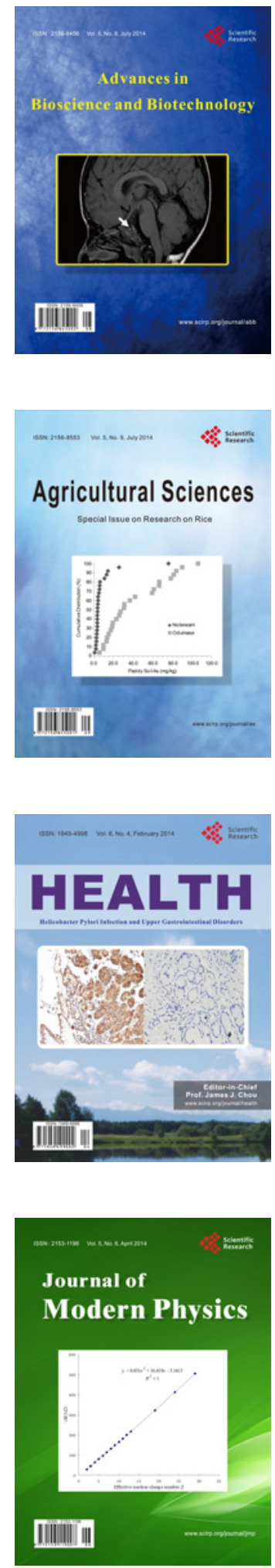
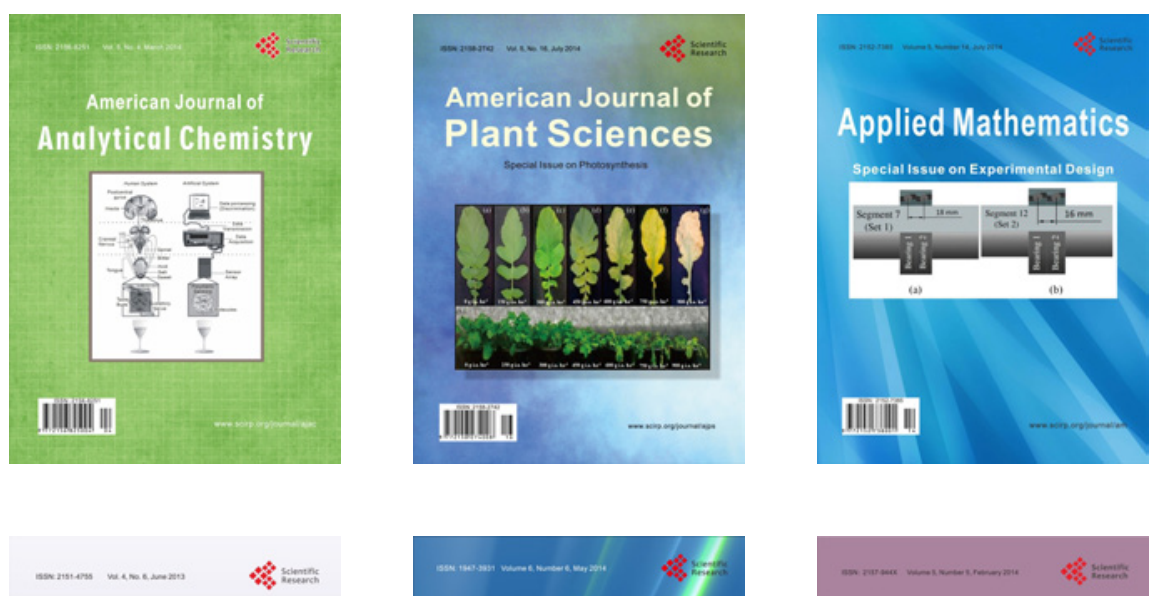

Creative Education
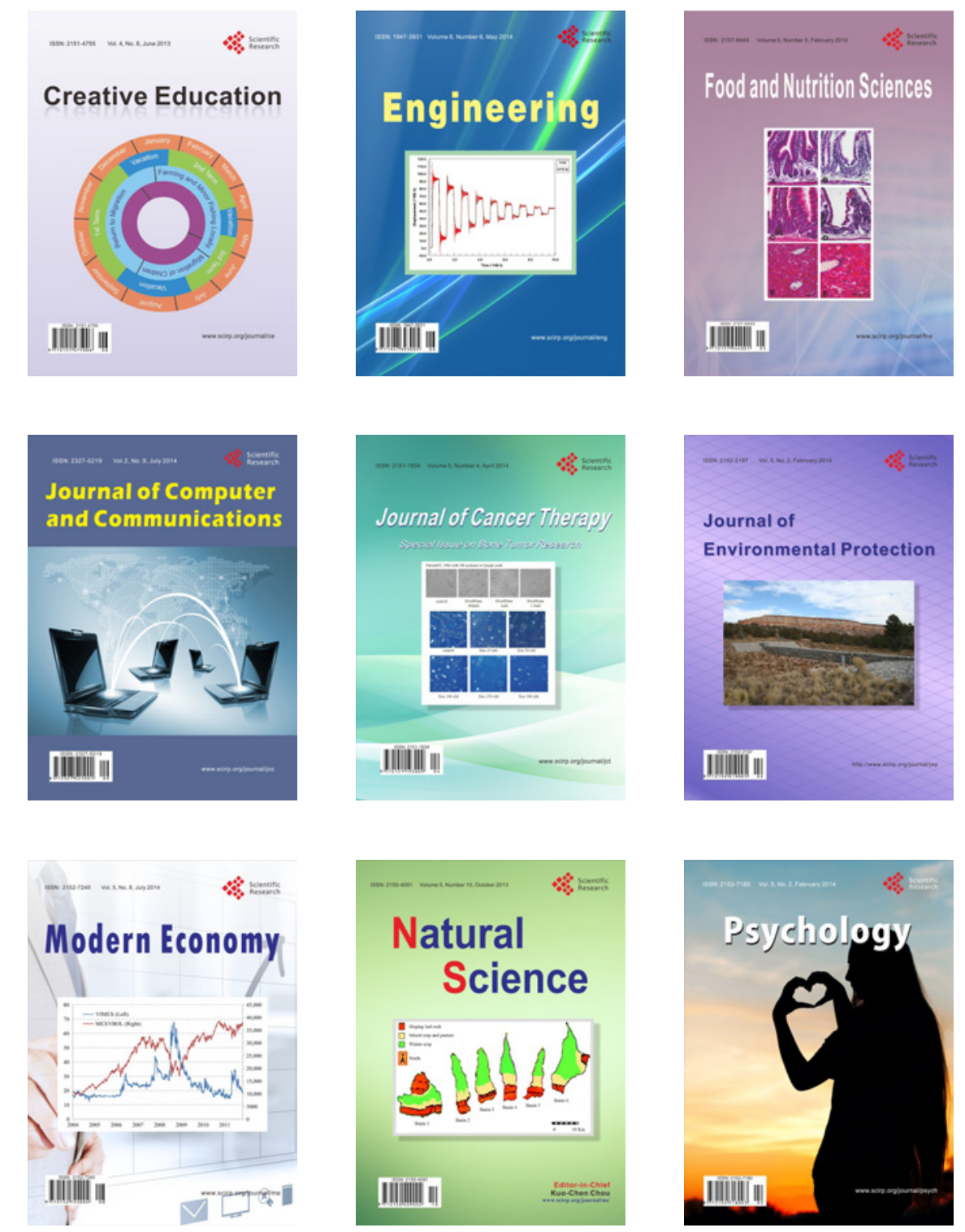